\title{
Pediculosis: a health problem in the camps of the Iranian former prisoners of war in Iraq
}

Dear editor,

Pediculosis or louse infestation remains a worldwide problem. The present letter is a report on the infestation of Iranian prisoners with body lice in the Iraqi camps during the Iraq-Iran conflict.

Body lice remain major vectors for diseases such as typhus, trench fever and relapsing fever. ${ }^{2}$ Epidemic typhus is normally associated with wars and other overcrowded unsanitary conditions such as those observed during human catastrophes when normal hygiene is disrupted.

Outbreaks of trench fever have been reported among homeless people ${ }^{5}$ and typhus disease has mainly been reported following military conflicts. ${ }^{1}$ The most important outbreak of this disease since World War II occurred in 1997 in Burundi (Africa) and involved more than 40,000 individuals. ${ }^{3}$

During the eight years of the Iraq-Iran conflict (19801988), more than 42,000 Iranian soldiers were captured (prisoners of war) and kept in Iraqi prisons for many years after the end of war (from 2.5 to more than 15 years). There were more than 23 detention camps for former Iranian prisoners in Iraq: six camps in Ramadi (in the west of Iraq), four camps in Mosul (in the north of Iraq), and 13 camps in Tikrit (located in the center of Iraq). In addition, many unregistered Iranian prisoners were held in Abu Ghraib and al-Rashid in Baghdad. Their health conditions were poor in the detention camps and they were sometimes deprived of the most rudimentary medical supplies and facilities. For instance, in Ramadi, where the majority of prisoners were registered by delegations from the International Committee of the Red Cross (ICRC), the camps consisted of three to four parts and there were eight rooms in each part. During the first years, 50 people were kept in each room but later on, the number of prisoners was increased to 70 to 80 people in each room. After the ceasefire, this number increased to 100 people in each of the rooms. The rooms were 17.5 meters long and 5.5 meters wide. There were five windows on each side, but they were blocked on one side. The prisoners made a toilet and a small washbasin for dishes and other purposes. In fact, there was as little as $2 \mathrm{~m}^{2}$ for each prisoner. They did not have access to hot water for baths in the first year at all. In later years and at the best times, baths with hot water were only possible for the personnel in each room and they were limited to one day a week in the winters. Moreover, recreation time was limited, especially during the first months. There were two recreation times (one in the morning and one in the afternoon) for a total time of three hours. Because of the overcrowded conditions and the limitations of time and water for having baths and washing clothes, hygiene was poor and the prisoners were liable to be affected by many diseases.

Pediculosis was one of the health problems of the prisoners in the camps, especially during the first year of their captivity. Nearly all the prisoners were infected by body lice. To the best of our knowledge and from the records we received from the negotiating members of the ICRC in the camps, and despite the lack of reliable diagnoses and reports, there were no reports of typhus.

To control pediculosis, the prisoners washed their cloths at any time that was possible and they exposed their belongings and blankets to the sun one day a week. To prevent becoming hosts for lice and to stop lice from laying their eggs in the seams of clothes, the prisoners wore their clothes inside out (especially underwear). Thus, the seams of the clothes were not in contact with their bodies. Furthermore, they put their clothes in plastic bags and added detergent powder to the bags and left them for many days. Topical anti-pediculosis drugs were prescribed by the Iraqi authorities many months after the outbreak of the infestation. However, because of the limitations mentioned earlier, it seems that topical drugs were ineffective. In contrast, oral therapy might have been a suitable alternative for treatment in the prisoner-of-war camps. Such therapy is easier to administer and potentially safer than topical drugs. ${ }^{4}$ After spending one year in captivity, and by the beginning of the summer of the second year, the recreation time was increased and more access to water for baths and for washing clothes became possible. Consequently, hygiene practices improved. Clothes were washed and left outdoors under the sun for many hours. In addition, the prisoners became accustomed to captivity and its conditions. Finally, pediculosis was eradicated in the second year.

Ali Khaji, MD

Sina Trauma and Surgery Research Center Sina General Hospital, Medical Sciences University of Tehran Tehran, Iran 


\section{REFERENCES}

1. Foucault C, Brouqui P, Raoult D. Bartonella quintana characteristics and clinical management. Emerg Infect Dis. 2006;12(2):217-23.

2. Foucault C, Ranque S, Badiaga S, Rovery C, Raoult D, Brouqui P. Oral ivermectin in the treatment of body lice. J Infect Dis. 2006;193(3):474-6.

3. Ko CJ, Elston DM. Pediculosis. J Am Acad Dermatol.
2004;50(1):1-12

4. Patterson KD. Typhus and its control in Russia, 18701940. Med Hist. 1993;37(4):361-81.

5. Raoult D, Ndihokubwayo JB, Tissot-Dupont H, Roux V, Faugere B, Abegbinni R. Outbreak of epidemic typhus associated with trench fever in Burundi. Lancet. 1998;352(9125):353-8. 